Document downloaded from:

http://hdl.handle.net/10251/94490

This paper must be cited as:

Hidalgo Signes, C.; Martínez Fernández, P.; Medel Perallon, E.; Insa Franco, R. (2017).

Analysis of the vibration alleviation of a new railway sub-ballast layer with waste tyre rubber. Materials and Structures. 50(2):1-13. doi:10.1617/s11527-016-0951-0

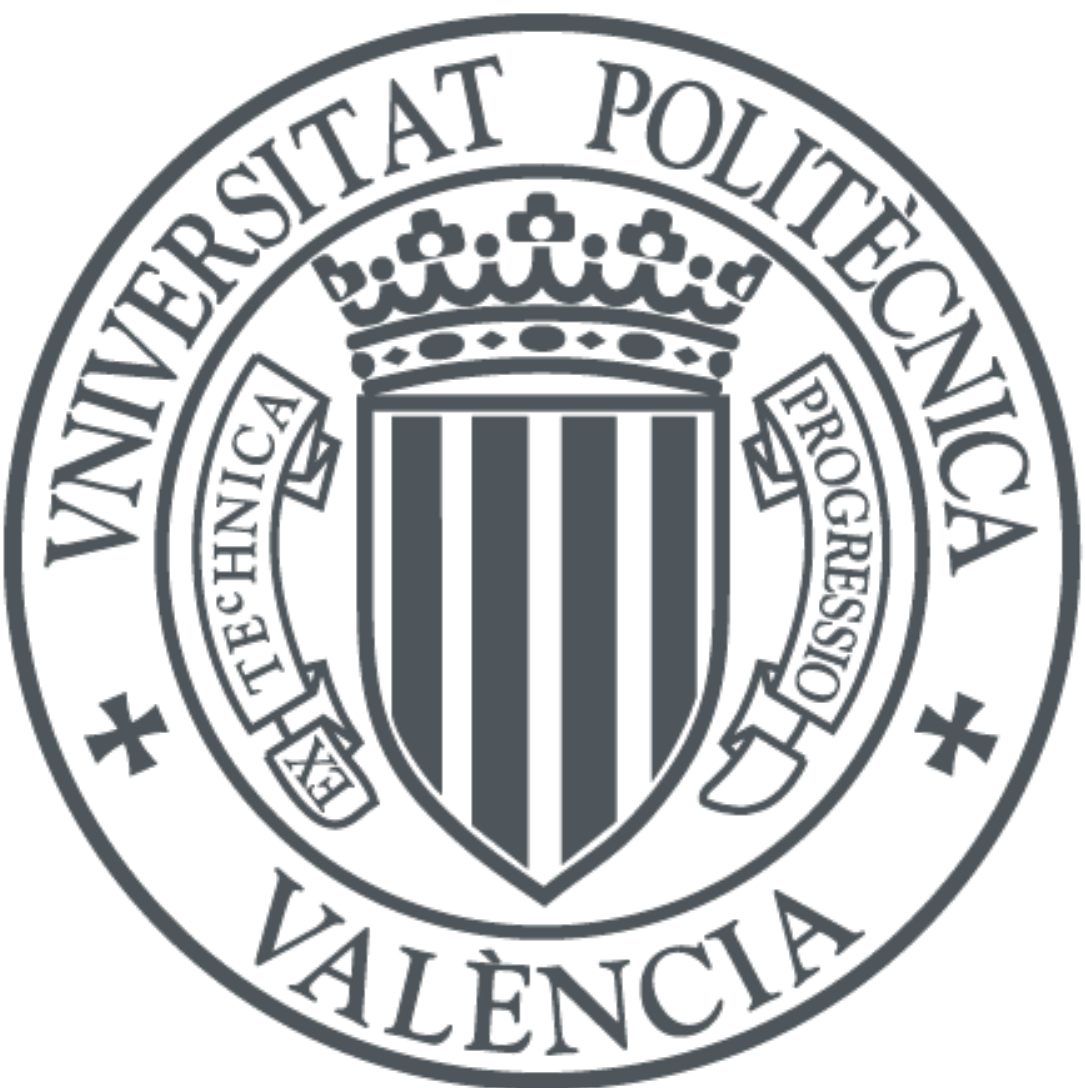

The final publication is available at

http://doi.org/10.1617/s11527-016-0951-0

Copyright Springer - RILEM Publishing

Additional Information 


\title{
ANALYSIS OF THE VIBRATION ALLEVIATION OF A NEW RAILWAY SUB-BALLAST LAYER WITH WASTE TYRE RUBBER
}

Carlos Hidalgo Signes, ${ }^{1}$ Pablo Martínez Fernández, ${ }^{2}$ Elías Medel Perallón, ${ }^{3}$ Ricardo Insa Franco 4 *

\begin{abstract}
This paper focuses on the assessment of the vibration behaviour of granular subballast materials mixed with rubber particles from scrap tyres. The main objective is to evaluate whether these mixes attenuate vibrations caused by passing trains, and if so, to what extent. Several laboratory and field tests were carried out to monitor the response of such materials to various excitation sources. The results show that under controlled laboratory conditions, the addition of rubber (up to $5 \%$ by weight) greatly increases the damping ratio and reduces vibration. Field tests also show that higher percentages of rubber yield a significant alleviation of vibration caused by repetitive and harmonic loads that are similar to those produced by passing trains. An addition of $5 \%$ by weight yields a reduction of $50 \%$ in the mean acceleration peak at one metre from the excitation source. The anisotropy of the mix is another key factor when evaluating the vibration behaviour of these mixes.
\end{abstract}

Keywords: railways; sub-ballast; waste tyres; rubber-aggregate mix; vibration alleviation

Original article: Materials and Structures, 50 (2), 102. doi: 10.1617/s11527-016-0951-0

"The original publication is available at the publisher's web site" (http://link.springer.com/journal/11527). The copyright to this article is transferred to RILEM.

Received: 24 February 2015 / Accepted: 19 September 2016. Published online: 19 November 2016 (C) Rilem 2016

\footnotetext{
${ }^{1}$ Geological engineer. Laboratory technician, Geotechnical Laboratory, Department of Geotechnical and Geological Engineering. Universidad Politécnica de Valencia (UPV). Camino de Vera, s/n, 46022, Valencia, Spain. Email: chidalgo@trr.upv.es

${ }^{2}$ Civil engineer. Researcher, Department of Transport Engineering and Infrastructure. Universidad Politécnica de Valencia (UPV). Camino de Vera, s/n, 46022, Valencia, Spain. Email: pabmarfe@cam.upv.es

${ }^{3}$ Laboratory technician, Roads Laboratory, Department of Transport Engineering and Infrastructure. Universidad Politécnica de Valencia (UPV). Camino de Vera, s/n, 46022, Valencia, Spain. Email: emedelp@tra.upv.es

${ }^{4} \mathrm{PhD}$ civil engineering. Railways professor, Department of Transport Engineering and Infrastructure. Universidad Politécnica de Valencia (UPV). Camino de Vera, s/n, 46022, Valencia, Spain. Email: $\underline{\text { rinsa@tra.upv.es }}$
}

*Corresponding author. Phone: +34 963877007 Ext. 73767 


\section{Introduction}

Scrap tyres are a troublesome waste material as they are produced in large quantities and their disposal is problematic. Alternatives have been proposed in recent years to deal with this environmental issue, and a promising suggestion is to use scrap tyres as a building material for large infrastructures such as roads and railways.

We propose a new mix of granular material and rubber shreds from scrap tyres as a sub-ballast layer in new railway lines. Sand-rubber mixtures (Yoon et al., 2005; Nakhaei et al., 2012) and bitumenrubber (Buonanno and Mele, 2012; Di Mino et al., 2012) mixtures have been studied in depth in recent years, but mixing rubber particles with coarse aggregates is a relatively unexplored alternative. The addition of rubber will enable reusing an otherwise useless waste material and may also provide added benefits such as vibration alleviation.

As a first step in the study of rubber and granular material mixtures, an extensive set of laboratory and field tests were carried out to assess the physical, chemical, and mechanical properties of such mixtures (Hidalgo et al., 2014). It was found that the addition of up to 5\% of rubber particles (by weight) yields certain improvements in terms of resistance to degradation while providing enough bearing capacity and resilient modulus. The mixture fulfilled all the usual requirements for materials used as sub-ballast in railway tracks.

As a second step of research, we aim to further assess the behaviour of these mixes, focusing on their promising potential for vibration alleviation. One of the main issues regarding the development of railways, particularly in urban areas, is that they are a source of noise and vibration which may disturb residents. This phenomenon has been extensively studied in recent years, both from a theoretical point of view (Thompson, 2009; Auersch, 2005) and practical point of view (Di Mino and Di Liberto, 2007). Various solutions have been proposed to mitigate ground-borne vibrations, such as elastic mattresses (Alves et al., 2012) and open and filled trenches (Karlström and Boström, 2007), and somewhat irregular results have been produced. However, less attention has been paid to the improvement of traditional construction materials and this approach may provide a more integrated solution (one example of this type of solution is described in Wolfe et al., 2004). 
We aim to determine whether these mixes provide a mitigation of the transmitted vibration and to what extent and in which range of frequencies. A broad array of laboratory and field tests were carried out and the results have been carefully analysed.

\section{Materials and methods}

To assess the potential attenuation of the new rubber-aggregate unbound mixes, several laboratory and field tests were carried out. These tests are described below.

\subsection{Laboratory tests}

There is no specific test to measure the vibration behaviour of granular mixes such as those studied in this paper. Therefore, new ad hoc laboratory tests were designed that followed standard procedures and previous published works: UNE EN 29052-1:89; ASTM C215:02; and the 'Free-Free Resonance Testing of In Situ Deep Mixed Soils' developed by Guimond-Barrett et al. (2013) in the IFFSTAR laboratory. These works were taken into account as a base to define the tests described in this paper, with variations due to the specific characteristics of the mixes. It is worth noting that to determine the precise testing protocols, several attempts were made to assess the influence of factors such as impact force, sample size, and sampling frequency. The procedures described are the product of these preliminary tests.

Three different mixes were tested - with rubber percentages ranging from $1 \%$ to $2.5 \%$ and $5 \%$ respectively (by weight). Rubber particles were sized between 1 and $20 \mathrm{~mm}$, with a low percentage of fibres and no steel wires. The aggregate material was sampled according to the sub-ballast requirements found in the Pliego de Prescripciones Técnicas Generales de Materiales Ferroviarios PF-7: Subbalasto (2006) and the Pliego de Prescripciones Técnicas Tipo para los proyectos de Plataforma PGP-2008 issued by the Spanish Ministry of Public Works and the main Spanish railway infrastructure organisation (ADIF) respectively. An unbound granular material, typically used as traditional sub-ballast, was also tested as a pattern to compare the results with those of the various mixes. For a detailed characterisation of the physical, chemical, and mechanical properties of the mixes and their constitutive components see Hidalgo et al. (2014).

Test specimens were cylinders with the same size and shape used for the Standard Proctor Test, although some variations were made depending on the type of test applied. All specimens were 
compacted to at least $99 \%$ of their maximum dry density for optimal Proctor moisture. It is important to consider that the addition of rubber in the percentages considered has very little influence on the optimal humidity, as seen in Fig. 1. This was also observed by Singh and Vinot (2011).

Two tests were performed. The first was a longitudinal test to evaluate the resonant frequency of the sample when excited in a direction parallel to the cylinder axis. The second test, called flexional, determined the resonant frequency of the sample when excited in a direction perpendicular to such axis.

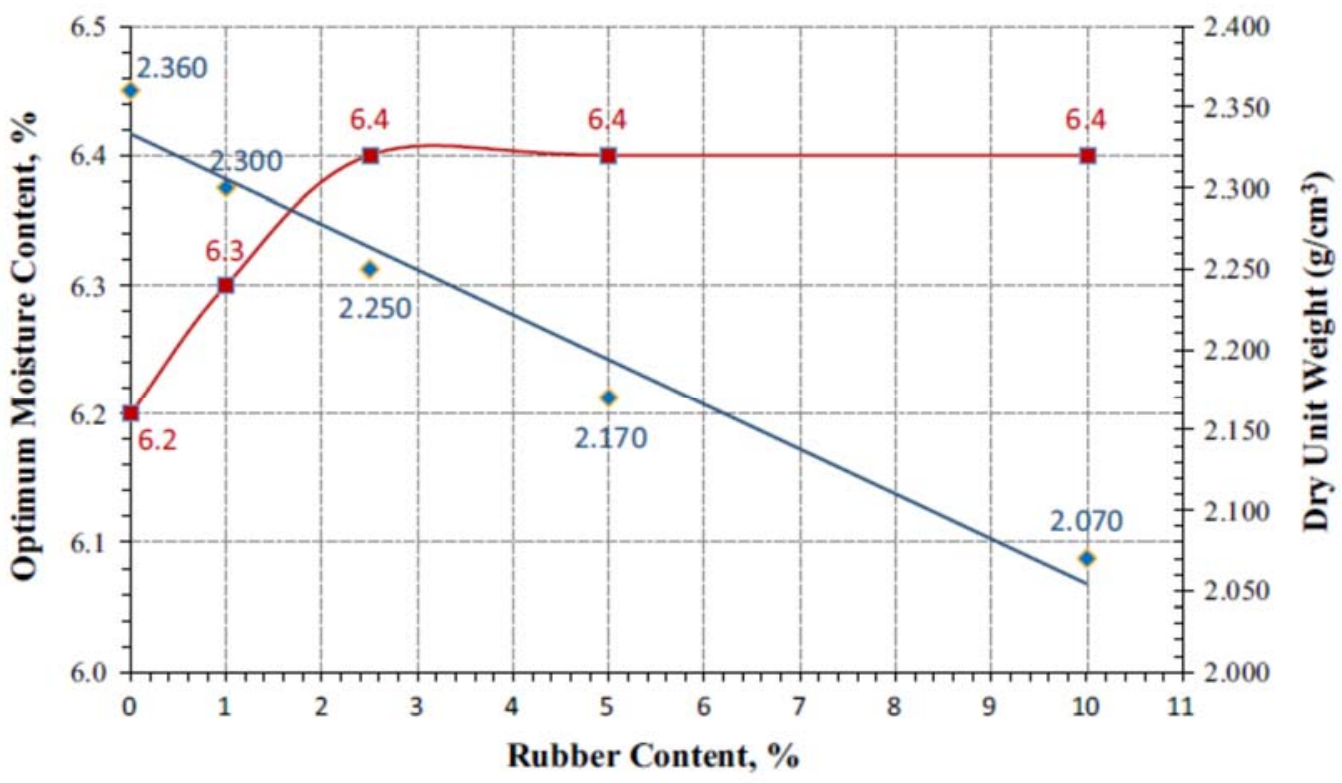

Fig. 1 Optimum moisture content and dry unit weight vs. \% rubber content

\subsubsection{Longitudinal test}

Preliminary attempts found that the best height-to-diameter ratio for the specimens was about 0.45 . Samples were placed on an elastic mattress (Fig. 2a) and hit by a metallic ball (diameter $9.97 \mathrm{~mm}$ and weight $4.10 \mathrm{~g}$ ) falling from a fixed height of $100 \mathrm{~mm}$. As shown in the picture, a metallic piece was added to the top of the specimen to avoid excessive damage (as the rubber-aggregate mix is unbound and therefore shows no cohesion) after several hits. Characteristics of all the samples tested are detailed in Table 1. 


\begin{tabular}{|c|c|c|c|c|}
\hline \multicolumn{5}{|c|}{ Longitudinal test } \\
\hline Sample & \% Rubber & $\varnothing(\mathrm{mm})$ & $\mathbf{H}(\mathbf{m m})$ & Dry density $\left(\mathrm{g} / \mathrm{cm}^{3}\right)$ \\
\hline SUB-BALLAST & 0 & 101.91 & 43.45 & 2.347 \\
\hline SUBMIX 1\% & 1 & 102.69 & 45.00 & 2.280 \\
\hline SUBMIX $2.5 \%$ & 2.5 & 103.50 & 45.66 & 2.231 \\
\hline SUBMIX 5\% & 5 & 102.00 & 49.33 & 2.152 \\
\hline \multicolumn{5}{|c|}{ Flexional test } \\
\hline Sample & \% Rubber & $\varnothing(\mathbf{m m})$ & $\mathbf{H}(\mathbf{m m})$ & Dry density (g/cm3) \\
\hline SUB-BALLAST & 0 & 101.52 & 132.00 & 2.338 \\
\hline SUBMIX 1\% & 1 & 102.05 & 129.06 & 2.278 \\
\hline SUBMIX $2.5 \%$ & 2.5 & 101.91 & 126.80 & 2.243 \\
\hline SUBMIX 5\% & 5 & 102.76 & 140.56 & 2.149 \\
\hline
\end{tabular}

Table 1: Longitudinal and flexional samples characteristics

Vibrations in the sample were recorded using a piezoelectric accelerometer (PCO 352A21) glued to the bottom of the specimen. Data was recorded with an amplifier (PCO 480C02) and an oscilloscope (Rigol DS1062) and then stored in a computer for post-processing.

\subsubsection{Flexional test}

Samples for the flexional test were similar to those for the longitudinal test, except for the cylinder height - which yielded a height-to-diameter ratio of 1.29 (in this case, with no modification from the Standard Proctor specimen size). Table 1 details the characteristics of the samples.

The same equipment was used for the testing procedure. Only the relative position of the elements was modified with respect to the longitudinal test - as shown in Fig. 2b. The sample was placed horizontally over an elastic mattress, with the accelerometer located on one side of the sample and the impact spot (once again reinforced with a metallic piece) on the other side.

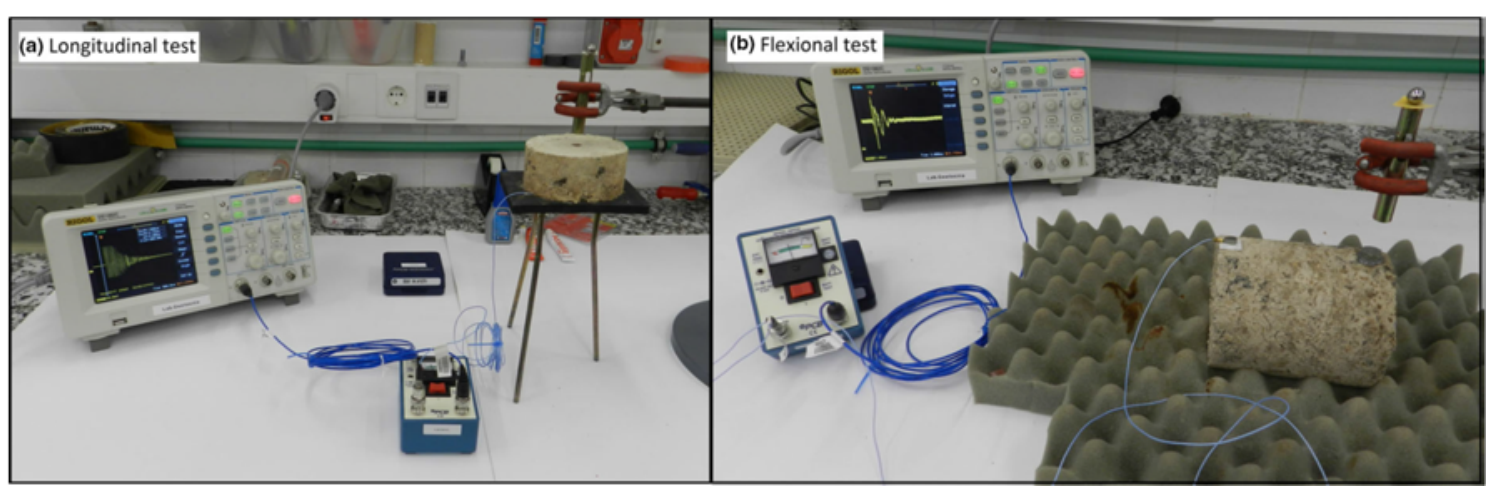

Fig. 2 a) Longitudinal test layout. b) Flexional test layout 


\section{2. $\quad$ Field tests}

While laboratory tests were designed to evaluate certain characteristics of the new mixes (namely damping ratio), field tests aimed to assess the performance of the mixes under circumstances closer to those of a railway track. To this end, an experimental railway platform was built.

This platform consists of a 10x10 m square, with a $35 \mathrm{~cm}$ thick underground layer of aggregate that represents the railway platform. Over this foundation, a second layer $(30 \mathrm{~cm})$ was laid that represents the sub-ballast. This layer was divided into four sections, each accounting for one of the three mixes studied $(1 \%, 2.5 \%$ and $5 \%$ of rubber content by weight) and a fourth mix representing the traditional unmixed sub-ballast. A more detailed description of the experimental platform can be found in Hidalgo et al. (2014).

The CSWS (continuous surface wave system) test was chosen to characterise the vibration response of the sub-ballast layer as this is a common and well known test used to measure ground-borne wave propagation speed, and provides a shear modulus $\left(\mathrm{G}_{\max }\right)$ with depth. However, this test does not enable measuring wave speed in a layer as thin and as close to the surface as the sub-ballast layer designed for the experimental platform (the minimum depth where results can be obtained is $0.5 \mathrm{~m}$, which is well under the sub-ballast layer). This is clearly shown in Fig. 3. We therefore designed ad hoc test.

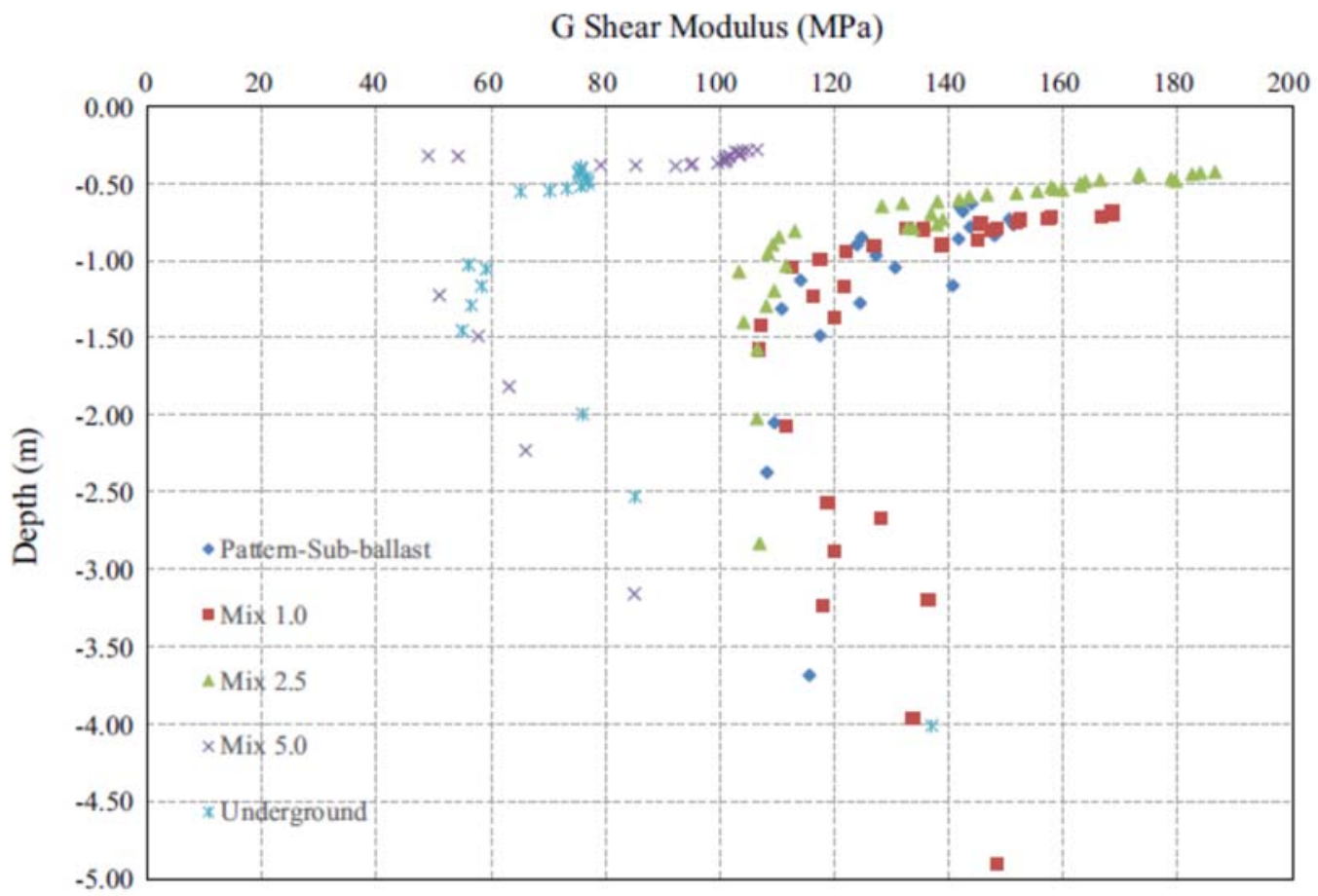

Fig. 3 Results from the CSWS test (shear modulus vs depth) 
Uniaxial piezoelectric accelerometers (MMF KS 76C-100) were glued to metallic spikes buried in each section of the sub-ballast layer. Data was recorded using a signal conditioner with a tenfold amplification of the acceleration levels registered. The excitation source was a pneumatic hammer (KANGO 900 Series) that exercises an energy blow of $16.4 \mathrm{~J}$ with a frequency of about $33 \mathrm{~Hz}$ (Fig. 4a). This was intended to represent a repetitive harmonic excitation similar to that caused by the passing of a train. It is clear that a train passing over a railway track excites a broad frequency band depending on several factors such as speed and track structure (Thompson, 2009). However, the frequency applied by the pneumatic hammer $(33 \mathrm{~Hz})$ is well within the usual frequency band measured in previous studies (Martínez et al., 2013).

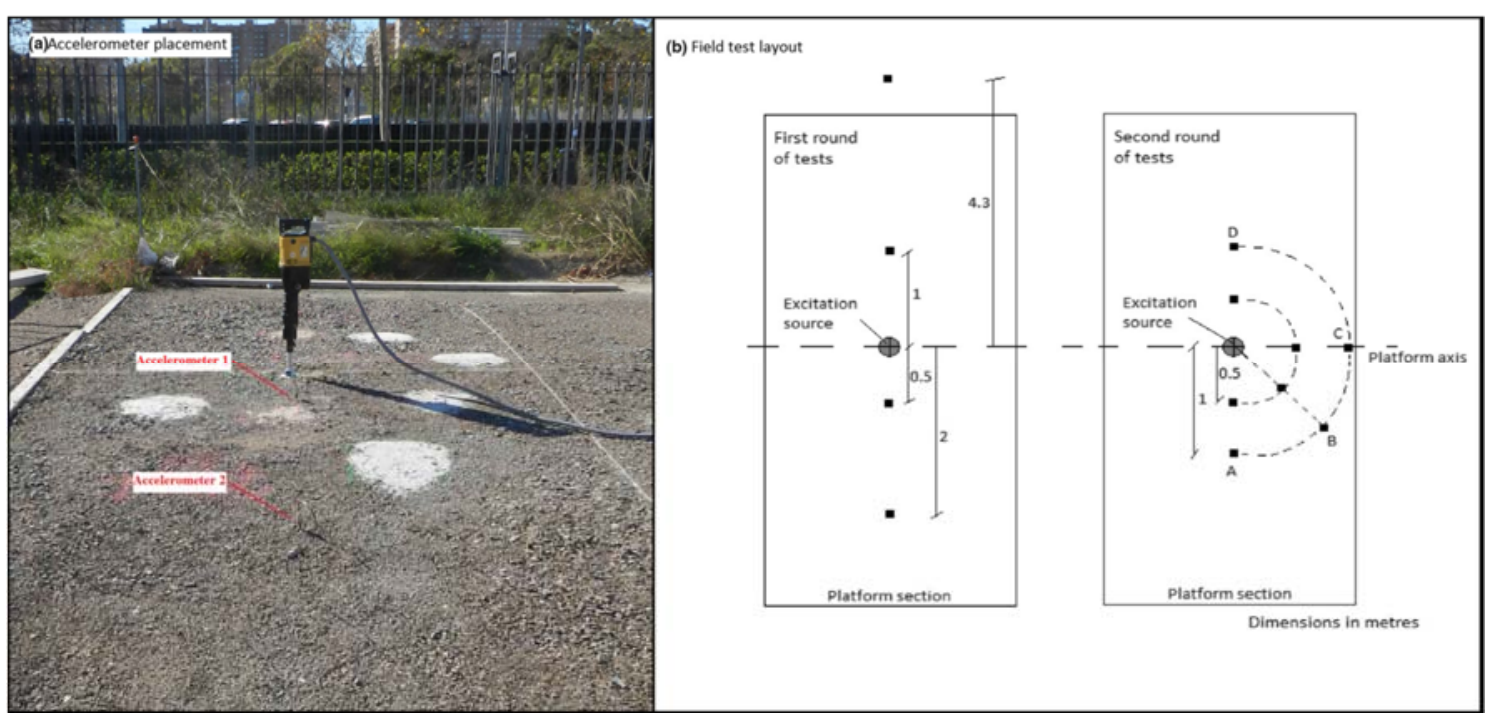

Fig. 4 a) Accelerometer placement. b) Field test layout

Measurements were carried out in two separate rounds. During the first round, the pneumatic hammer was operated in the centre of each section and the resultant acceleration was measured at $0.5,1,2$ and 4.3 metres, the latter located beyond the limit of the experimental platform. As the data gathered from this initial test was insufficient, a second round was carried out within the pattern and 5\% mix sections. Sensors were placed at 0.5 and 1 metre in four directions (A, B, C and D) radiating from the section centre so as to account for the potential heterogeneity of the materials (Fig. 4b). Three tests were run for each of the four sensor configurations. 


\subsection{Data processing}

Accelerations from the laboratory tests were recorded at a very high sampling frequency $\left(10^{8} \mathrm{~Hz}\right)$ and exported to MATLAB (The Mathworks, Inc., Natick, MA, USA). Vibration spectra were obtained using the fast Fourier transform (FFT) so as to identify the resonant frequency. Additionally, the exponential envelope of the time-based signal was obtained by means of the Hilbert transform, and then the damping ratio $(\xi)$ was calculated from the regression curve of the envelope (free decay method):

$\xi=\frac{|\mathrm{K}|}{2 \pi f_{0}}$

where $\mathrm{f}_{0}$ is the resonant frequency and $\mathrm{K}$ is the exponential regression coefficient.

Data from field tests was measured with a sampling frequency of $2500 \mathrm{~Hz}$ and exported to MATHEMATICA (Wolfram Research Inc., Champaign, Illinois, USA), where vibration spectra were calculated and a high pass filter $(0.5 \mathrm{~Hz})$ was applied to eliminate low frequency noise. 1/3 octave spectra were also obtained as they provide a better insight of the distribution of the signal in the frequency bands that most affect humans (ISO 2631-2:2003).

No damping ratio was calculated from field data as these measurements are far more heterogeneous and affected by many uncontrolled factors (such as irregularities in the load application and signal noise) than those obtained from carefully controlled laboratory tests. An index was calculated to quantify variations between materials, as defined below:

$C I=\frac{a_{m}}{a_{p}} \times 100$

Where $C I$ (Continuity Index) is the aforementioned index, $a_{m}$ is the mean acceleration peak measured in each sample mix, and $a_{p}$ is the mean acceleration peak measured in the pattern material (i.e. the unmixed sub-ballast). In this way, the mean acceleration peak registered at each position is normalised with regards to the equivalent acceleration peak from the pattern material. 


\section{Results and discussion}

In this section, the results obtained from both the laboratory and field tests are presented and discussed.

\subsection{Laboratory tests}

Figure 5 shows the accelerograms measured for four specimens (unmixed sub-ballast, 1\% mix, 2.5\% mix and 5\% mix) during the longitudinal test. There is a clear attenuation of the acceleration as more rubber is added to the mix, to the point that the acceleration peak presents a tenfold reduction between the unmixed sub-ballast and the 5\% mix.
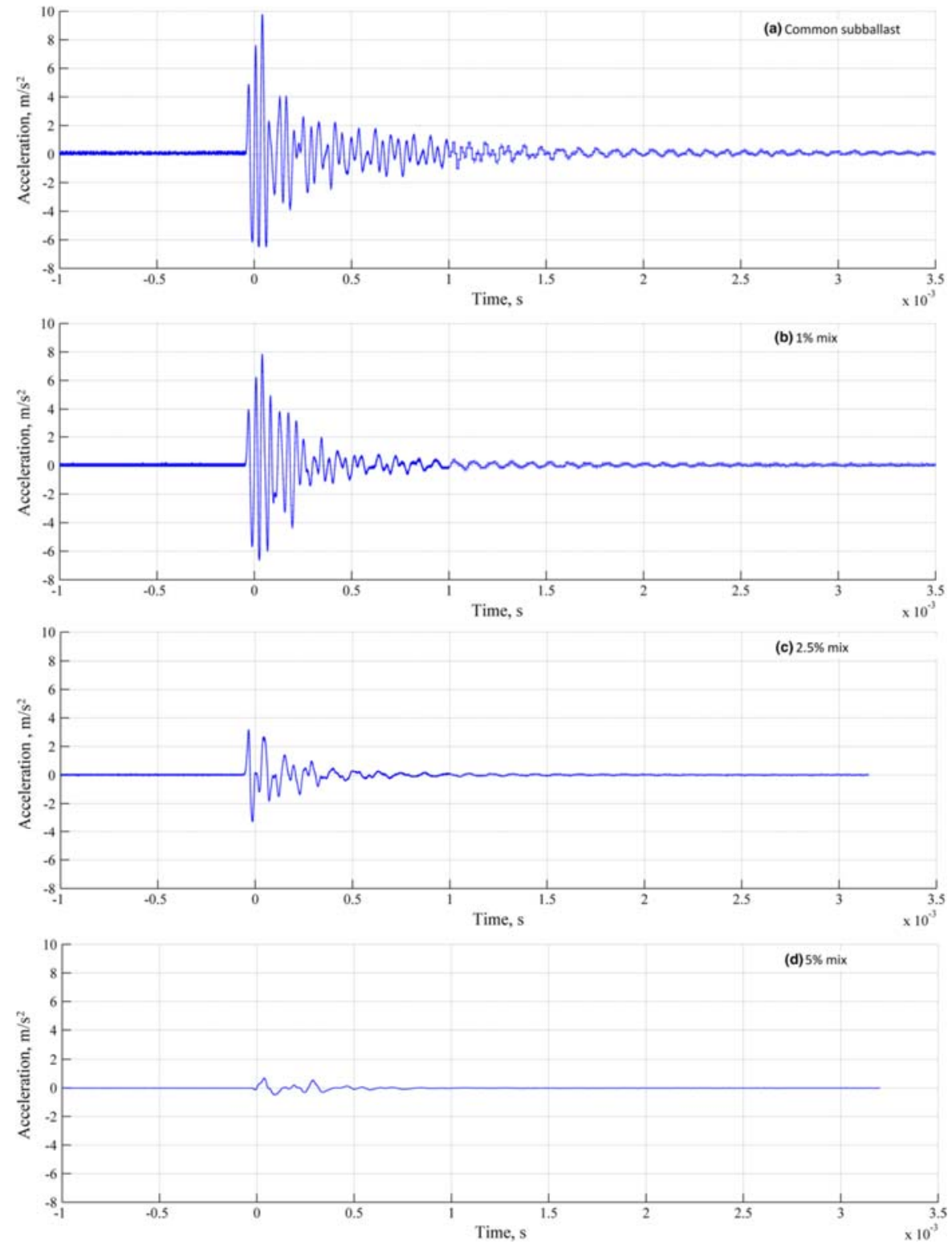

Fig. 5 Acceleration registered during the longitudinal test: a) common sub-ballast. b) $1 \%$ mix.

c) $2.5 \%$ mix. d) $5 \%$ mix 
This behaviour is further confirmed as the damping ratio $(\xi)$ increases noticeably when more rubber is added (Table 2). This increase fits the results obtained in previous studies (Feng and Sutter, 2000). The resonant frequency $\left(f_{0}\right)$ is reduced: from over $10 \mathrm{KHz}$ in the common sub-ballast to $7.6 \mathrm{KHz}$ in the $5 \%$ mix.

\begin{tabular}{lccc}
\hline Sample & $\mathbf{f}_{\mathbf{0}} \mathbf{( H z )}$ & Damping ratio $\xi$ & $\begin{array}{c}\text { Maximum acceleration } \\
\left(\mathbf{m} / \mathbf{s}^{2}\right)\end{array}$ \\
\hline SUB-BALLAST & 10530 & 0.046 & 8.39 \\
SUBMIX 1\% & 10141 & 0.077 & 7.31 \\
SUBMIX 2.5\% & 8702 & 0.099 & 3.20 \\
SUBMIX 5\% & 7670 & 0.106 & 0.66 \\
\hline
\end{tabular}

Table 2: Results from the longitudinal test

The corresponding vibration spectra (Fig. 6) show two main acceleration peaks: one at $10 \mathrm{KHz}$; and another one at about $25 \mathrm{KHz}$ in the pattern material (Fig. 6a). Both peaks are consistently attenuated as the rubber content increases, until the peak at $25 \mathrm{KHz}$ is completely mitigated in the $5 \%$ mix (Fig. $6 \mathrm{~d})$, while the $10 \mathrm{KHz}$ peak was reduced by one order of magnitude.
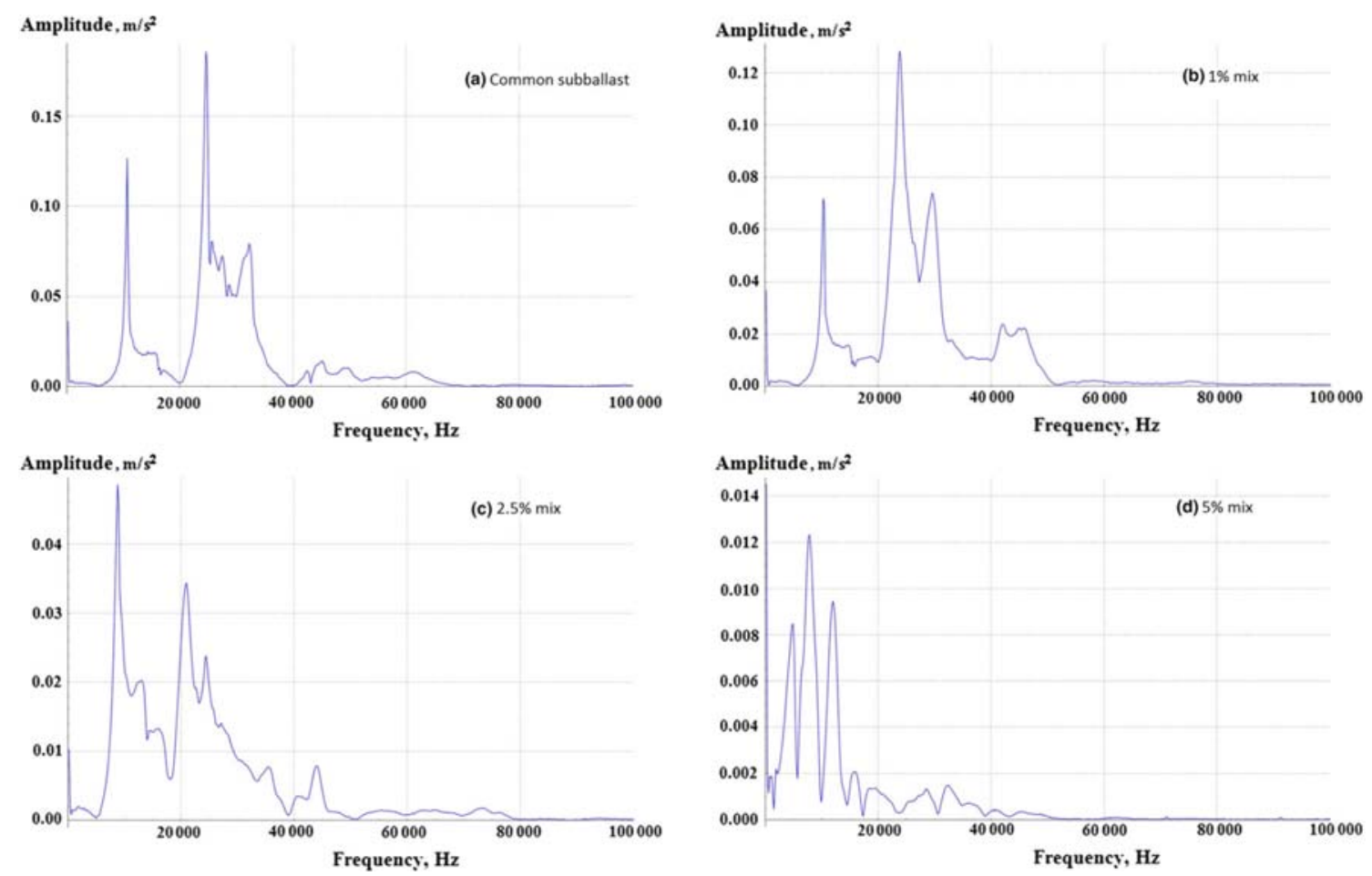

Fig. 6 Vibration spectra registered during the longitudinal test: a) common sub-ballast. b) $1 \%$ mix. c) $2.5 \%$ mix. d) $5 \%$ $\operatorname{mix}$ 
The results from the flexional test follow the same trend. As Figure 7 shows, a clear mitigation is observed in the samples, with a magnitude similar to that of the longitudinal test. The damping ratio increases with the addition of rubber, and the resonant frequency decreases once again from over 10 KHz to barely $8 \mathrm{KHz}$ (Table 3 ).

\begin{tabular}{lccc}
\hline \multicolumn{1}{r}{ Sample } & $\mathbf{f}_{\mathbf{0}} \mathbf{( H z )}$ & Damping ratio & $\begin{array}{c}\text { Maximum acceleration } \\
\left(\mathbf{m} / \mathbf{s}^{2}\right)\end{array}$ \\
\hline SUB-BALLAST & 10476 & 0.040 & 2.71 \\
SUBMIX 1\% & 9532 & 0.079 & 1.47 \\
SUBMIX 2.5\% & 8476 & 0.098 & 0.83 \\
SUBMIX 5\% & 8015 & 0.119 & 0.26 \\
\hline
\end{tabular}

Table 3: Results from the flexional test
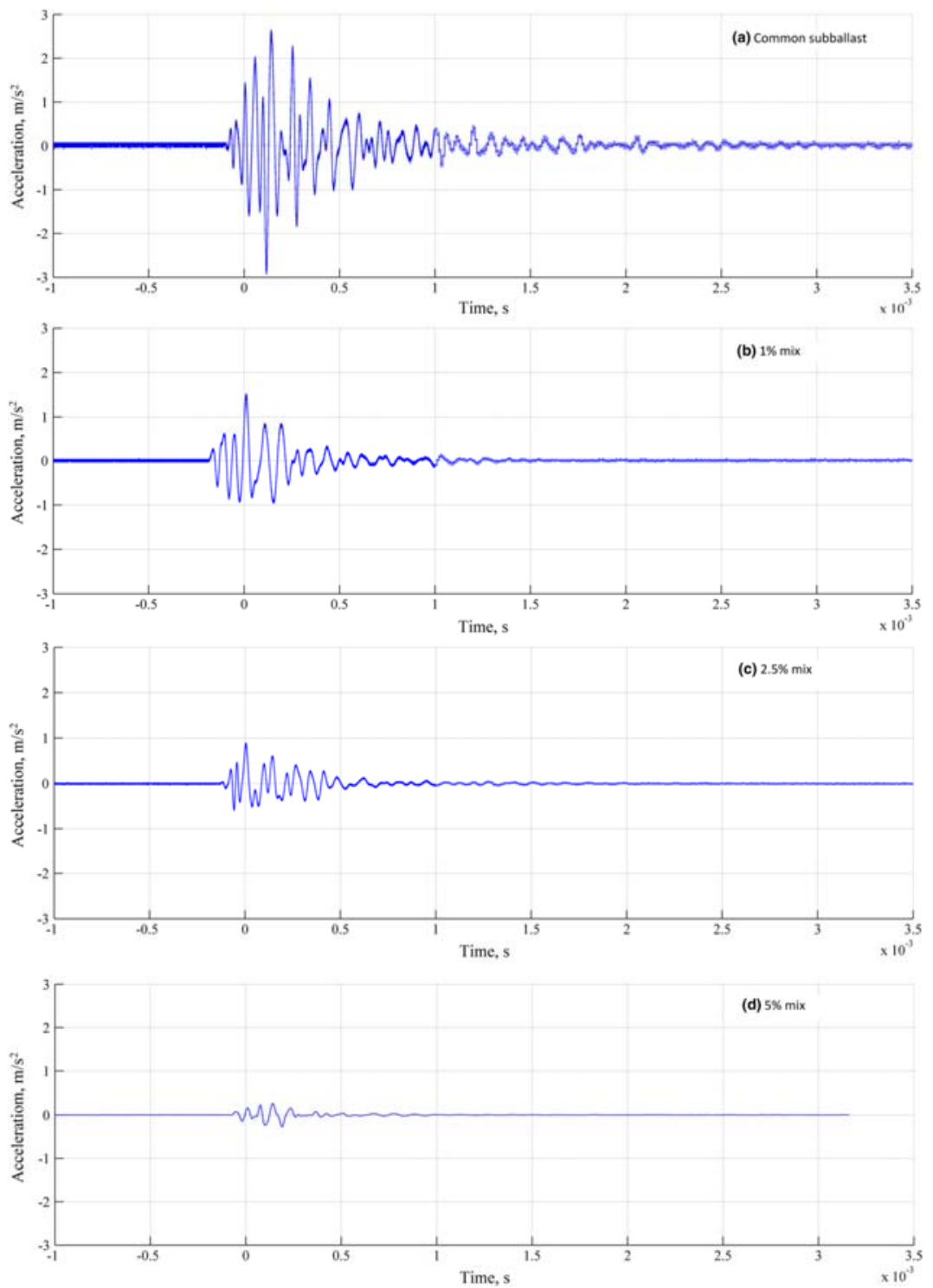

Fig. 7 Acceleration registered during the flexional test: a) common sub-ballast. b) $1 \%$ mix. c) $2.5 \%$ mix. d) $5 \%$ mix 
The vibration spectra shown in Figure 8 display two main peaks at 10 and $20 \mathrm{KHz}$, and a third smaller peak at about $33 \mathrm{KHz}$ in the pattern material (Fig. 8a). In the 1\% mix there is a shift of frequencies as the $20 \mathrm{KHz}$ peak moves towards $15 \mathrm{KHz}$, and the peak in $33 \mathrm{KHz}$ moves towards $25 \mathrm{KHz}$. Amplitude is also reduced.
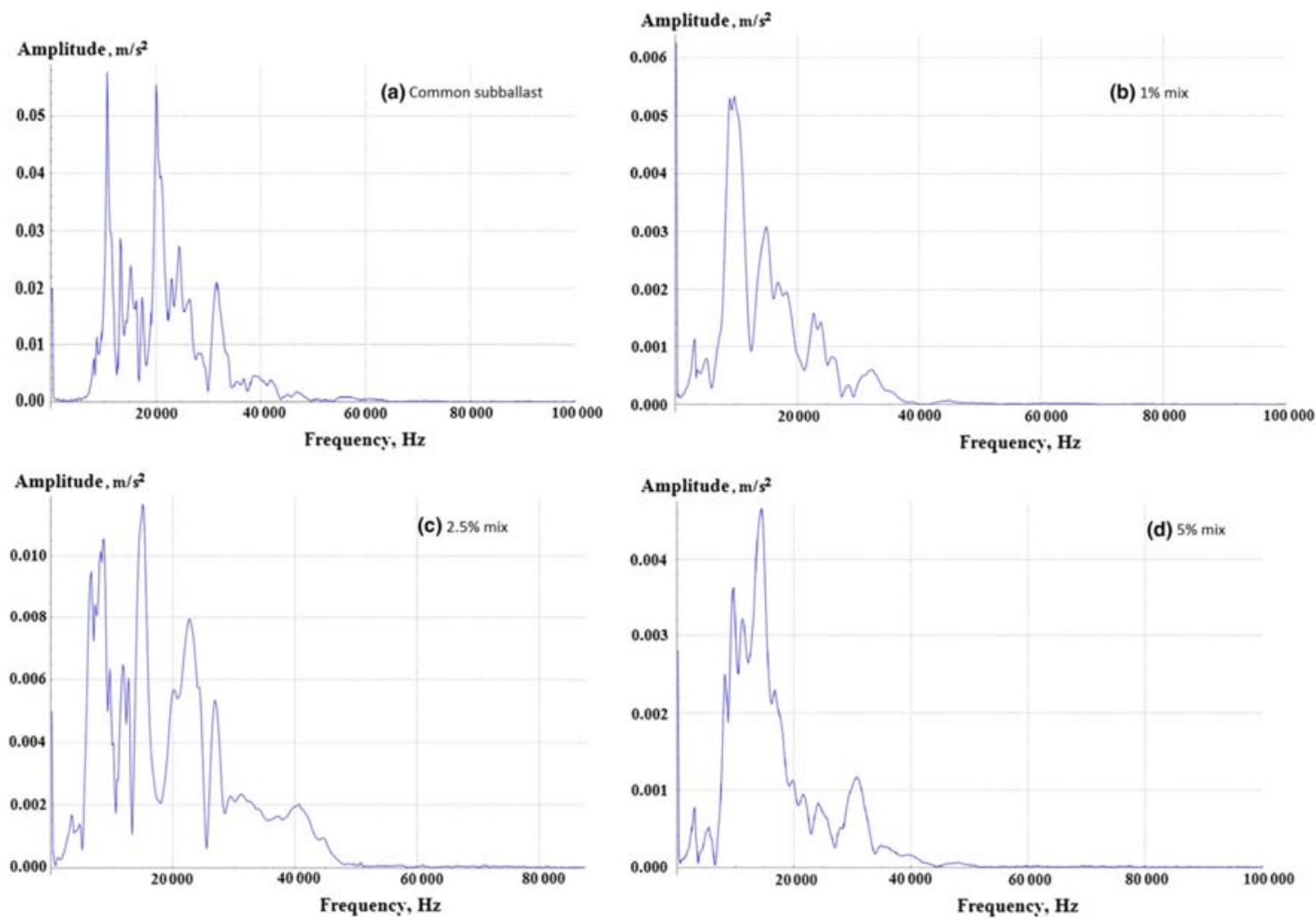

Fig. 8 Vibration spectra registered during the flexional test: a) common sub-ballast. b) $1 \%$ mix. c) $2.5 \%$ mix. d) $5 \%$ $\operatorname{mix}$

In the $2.5 \%$ mix, however, these peaks are greatly amplified (Fig. $8 \mathrm{c}$ ), a result that distorts the overall trend and may be caused by some irregularity in the specimen or the experimental process. Peaks are reduced to their lowest amplitude in the 5\% mix (Fig. 8d).

Considering the laboratory results, it can be concluded that under the tested conditions, the addition of rubber reduces the amplitude of vibration in the material. The damping ratio increases considerably with the addition of rubber in all cases.

\section{2. $\quad$ Field tests}

During the field tests, the pneumatic hammer was used as an excitation source so as to simulate a harmonic load similar to that caused by the passing of a train. Four configurations of two sensors were 
tested for each section. The first evident result is that the levels of vibration between sensors placed at the same distance from the excitation source differ considerably in all sections, despite applying the same harmonic load. An example of this is shown in Table 4.

\begin{tabular}{lll}
\hline \multicolumn{1}{c}{ Sensor configuration } & $\mathbf{0 . 5} \mathbf{~ m}$ & $\mathbf{1} \mathbf{~ m}$ \\
\hline A (Perpendicular 1) & 21.18 & 3.93 \\
B (Diagonal) & 24.90 & 6.06 \\
C (Parallel) & 42.79 & 4.57 \\
D (Perpendicular 2) & 38.63 & 8.66 \\
MEAN & 31.88 & 5.81 \\
\hline
\end{tabular}

Table 4: Mean acceleration peak $\left(\mathrm{m} / \mathrm{s}^{2}\right)$ in the unmixed subballast section (hammer)

Therefore, despite the careful mixing and layout of each material during the construction process of the experimental platform, these types of granular materials and mixes present a certain degree of anisotropy with regards to the transmission of mechanical waves. This affects the way the vibration is attenuated depending on the direction from the source.

However, despite this irregularity, certain trends can be observed when comparing the results between different materials. As Table 5 shows, there is a clear reduction in the mean acceleration peak as the content of rubber from scrap tyres increases. At 0.5 metres from the excitation source, the peak is halved in the $1 \%$ band $(\mathrm{CI}=56.46 \%)$ and even more so in the $2.5 \%$ and $5 \%$ bands $(\mathrm{CI}=38.58 \%)$.

At one metre from the source (position D) the trend is similar, as shown in Figure 9.

\begin{tabular}{lcccc}
\hline \multicolumn{1}{c}{ Section } & $\mathbf{0 . 5} \mathbf{~ m}$ & CI (0.5 m) & $\mathbf{1 ~ m}$ & CI (1 m) \\
\hline SUB-BALLAST & 31.88 & - & 5.81 & - \\
SUBMIX 1\% & 18 & $56.46 \%$ & 6.10 & $105 \%$ \\
SUBMIX 2.5\% & 12.30 & $38.58 \%$ & 4.15 & $71.43 \%$ \\
SUBMIX 5\% & 12.30 & $38.58 \%$ & 2.69 & $46.30 \%$ \\
\hline
\end{tabular}

Table 5: Mean acceleration peak and Comparison Index (m/ $/ \mathrm{s}^{2}$, all positions)

The accelerograms show a clear reduction of the acceleration peaks as the content of rubber from scrap tyres increases. Interestingly, the difference between the pattern material and the $1 \%$ mix is almost negligible (there is even a slight increase), but there is a clear mitigation in the $2.5 \%$ mix, and the signal registered in the $5 \%$ mix is less than half of that registered in the pattern $(\mathrm{CI}=46.30 \%)$. The 
same trend is observed for all sensor configurations and distances, despite the aforementioned irregularities.
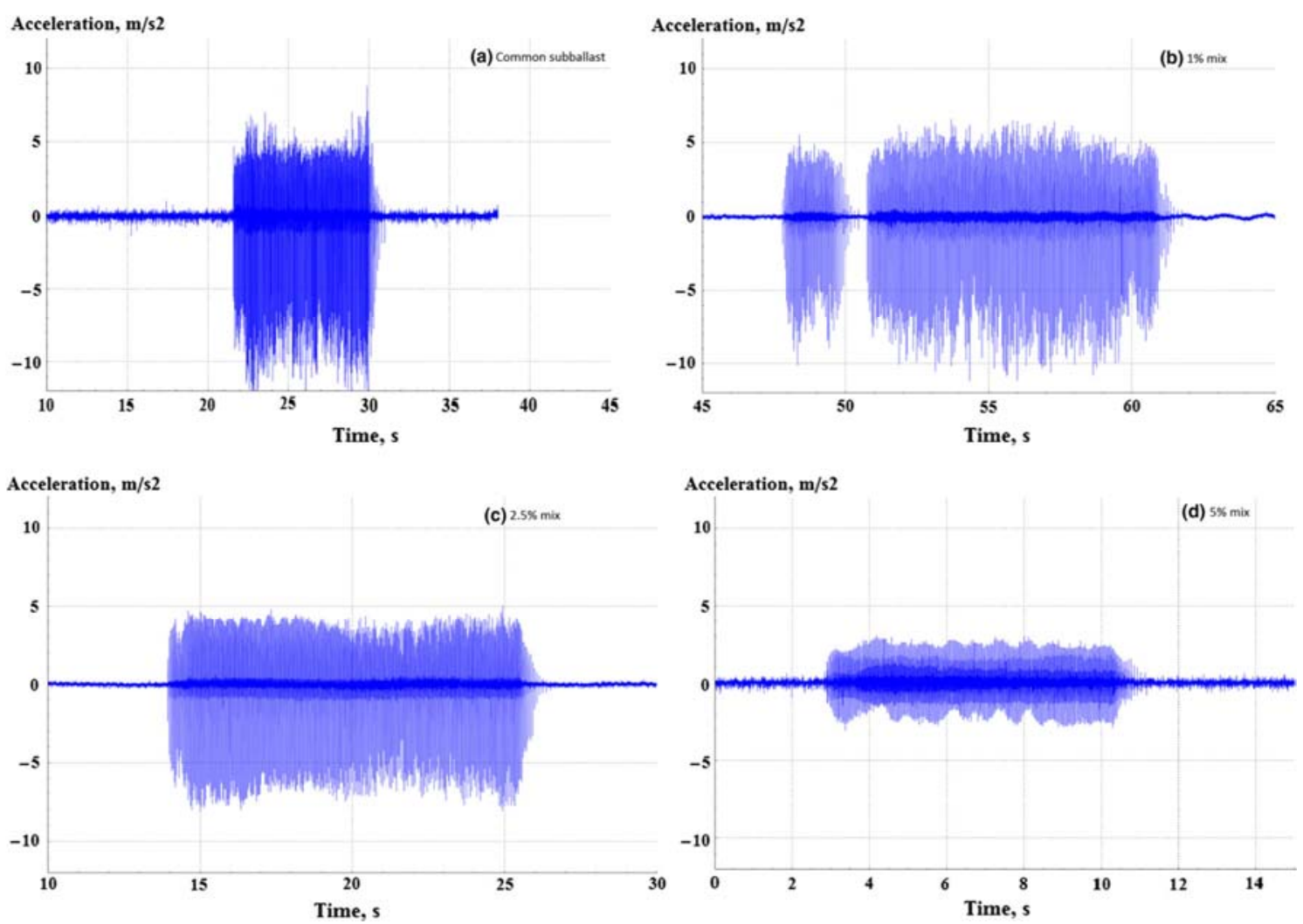

Fig. 9 Acceleration registered at one metre from the excitation source: a) common sub-ballast. b) $1 \%$ mix. c) $2.5 \%$ mix. d) $5 \% \operatorname{mix}$

When looking at the $1 / 3$ octave vibration spectra for the pattern and 5\% mix sections (Fig. 10, once again at one metre in position $\mathrm{D}$ ), there are two main frequency ranges excited by the pneumatic hammer: a lower range (between the 1 and $5.5 \mathrm{~Hz}$ band) and a higher broader range (over $125 \mathrm{~Hz}$ and up to $1000 \mathrm{~Hz}$ in the pattern soil). There is also a small but clear peak at 80-100 Hz. Both ranges present certain differences between the unmixed sub-ballast and the $5 \%$ mix, but the lower range suffers relatively small changes. The main peak at $1.6-2 \mathrm{~Hz}$ presents a similar value, while the lowest peaks $(1-1.25 \mathrm{~Hz})$ are slightly reduced in the $5 \%$ mix.

The higher band changes dramatically between both sections as the main peak shifts from 400 to 160 $\mathrm{Hz}$ between both sections and reaches a higher amplitude. Additionally, the highest frequencies (over $315 \mathrm{~Hz}$ and up to $1000 \mathrm{~Hz}$ ) are clearly reduced in the $5 \%$ mix with regards to the unmixed sub-ballast. 
Therefore, by applying a harmonic excitation of about $33 \mathrm{~Hz}$, two wide ranges of frequencies are activated in the ground. The lowest range is broadly similar in the traditional sub-ballast and the mix with $5 \%$ of rubber from scrap tyres, while the highest range presents important changes (partial mitigation and partial shift to a lower frequency band) that explains the overall reduction in the acceleration peak observed between the two sections.
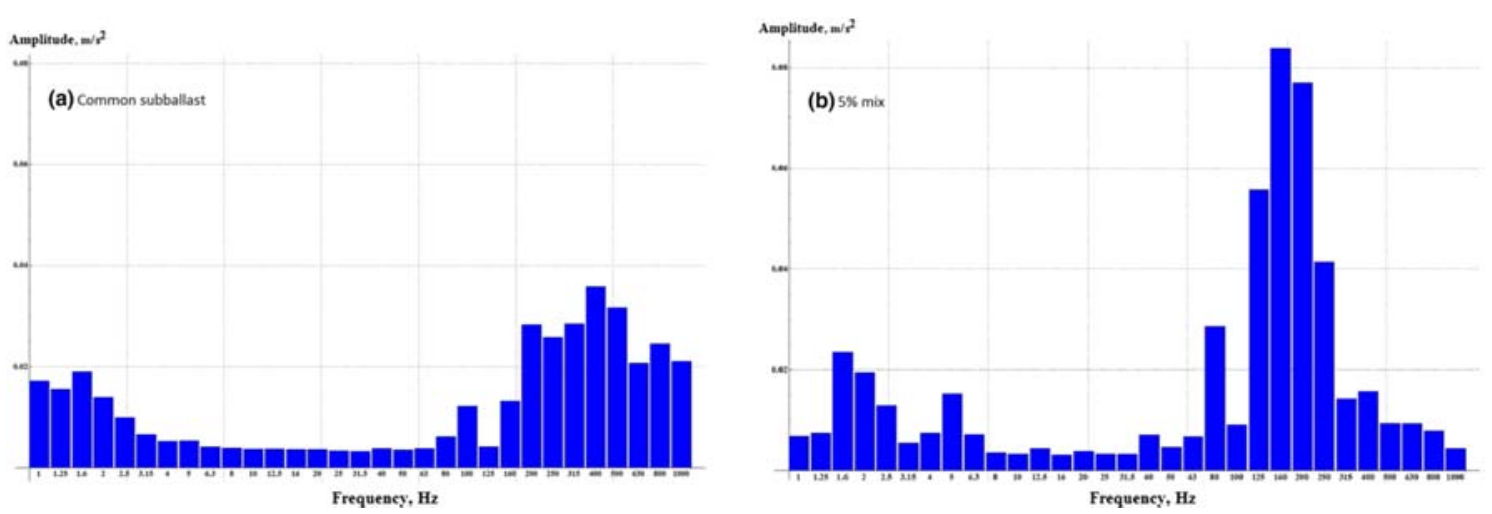

Fig. 10 1/3 octave spectra registered at one metre from the excitation source: a) common sub-ballast. b) 5\% mix

These results point out the remarkable importance of the material composition regarding its vibrational behaviour, as applying the same load frequency and amplitude to materials that are only slightly different excites fairly diverse frequency ranges. The addition of rubber increases the alleviation of the sub-ballast with regard to harmonic loads with a moderately high frequency (in terms of the usual values measured in railways), but has no observable effect for the lowest frequency band (which may be an important component of the complex load a train applies to the track).

\section{Conclusions}

This paper assesses the vibration behaviour of sub-ballast material mixed with different percentages of rubber particles from scrap tyres. This is a follow-up research from previous studies in which the suitability and mechanical properties of such mixes were assessed. Laboratory and field tests were carried out with different excitation sources to evaluate potential vibration alleviation. From the laboratory tests it is clear that, under these experimental conditions, the addition of rubber reduces the overall vibration of the sample. The damping ratio increases significantly with the percentage of rubber in longitudinal and flexional tests. The vibration spectrum is also consistently mitigated, although 
there is also a shift of peaks towards lower frequency bands (particularly for the flexional test). Therefore, rubber particles present a clear potential for vibration alleviation.

The field tests results, whose conditions are far more similar to those of a real track, confirm to a certain degree the behaviour of the mixed materials. First of all, it is clear that these mixes present a degree of anisotropy that influences behaviour. Secondly, the addition of rubber particles, even as a small fraction of the total weight, not only increases alleviation but remarkably affects the whole range of frequencies excited in the subballast despite applying always the same load with constant frequency and amplitude.

The addition of rubber seems to improve the attenuation of the vibration caused by a harmonic load, as the highest frequencies excited in the ground (i.e. over $300 \mathrm{~Hz}$ ) are clearly reduced. However, the lowest frequencies excited $(<2 \mathrm{~Hz})$ are barely affected.

In conclusion, the addition of rubber to traditional sub-ballast material presents a clear potential for vibration alleviation in the higher frequency band $(>300 \mathrm{~Hz})$ of the spectrum commonly excited by passing trains. The reduction measured in the field tests (in terms of mean acceleration peak) at 0.5 metres is about $60 \%$ for a rubber content of $2.5 \%$ or higher by weight, and about $50 \%$ for a rubber content of $5 \%$ at one metre from the excitation source. This clearly shows that adding rubber particles to granular sub-ballast provides a way of disposing of this problematic waste material and also yields a useful characteristic in the form of vibration mitigation.

To further assess the effectivity of these mixes and reach a sounder conclusion, it is necessary to test them in an real railway track under real traffic conditions, and so analyse behaviour under a broader frequency range.

\section{Acknowledgments}

The authors wish to thank GUEROLA for providing the soil samples from its quarry, EMRO for providing the rubber particles, and Ángel Morilla Rubio, Manolo Medel Perallón, and Esther Medel Colmenar for their help during field tests. 


\section{References}

ADIF. 'Pliego de Prescripciones Técnicas Tipo para los Proyectos de Plataforma PGP-2008 (Techical Specifications for Railway Platform Projects PGP-2008).'

AENOR (1994) UNE EN 29052-1:89. 'Acoustics - Determination of the dynamic stiffness. Part 1: Materials used under floating floors in dwellings.'

Alves P, Calçada R and Silva A (2012) 'Ballast mats for the reduction of railway traffic vibrations. Numerical study.' Soil Dynamics and Earthquake Engineering, 42:137-150.

Ansys Inc. (2010) ANSYS [Software], version 13.0, Canonsburg, Pennsylvania, USA.

ASTM (2002) C215:2002. 'Standard Test Method for Fundamental Transverse, Longitudinal, and Torsional Resonant Frequencies of Concrete Specimens.'

Auersch L (2005) 'The excitation of ground vibration by rail traffic: theory of vehicle-track-soil interaction and measurements on high-speed lines.' Journal of Sound and Vibration, 284(1):103132.

Buonanno A, and Mele R (2012) 'The use of bituminous mix sub-ballast in the Italian State Railways'. $2^{\text {nd }}$ Eurasphalt \& Eurobitume Congress, Barcelona, 20-22 September 2000.

Di Mino G and Di Liberto M (2007) 'Modelling and experimental survey on ground borne vibration induced by rail traffic.' $4^{\text {th }}$ International SIIV Congress, 12-14 September, 2007, Palermo, Italy.

Di Mino G, Di Liberto M, Maggiore C and Noto S (2012) 'A dynamic model of ballasted rail track with bituminous sub-ballast layer.' Procedia-Social and Behavioral Sciences, 53:366-378.

Feng ZY and Sutter KG (2000) 'Dynamic Properties of Granulated Rubber/Sand Mixtures.' Geotechnical Testing Journal, 23 (3):338-344.

Guimond-Barrett A, Nauleau E, Le Kouby A, Pantet A, Reiffsteck P and Martineau F (2013) 'FreeFree Resonance Testing of In Situ Deep Mixed Soils.' Geotechnical Testing Journal, 36 (2). DOI: $10.1520 / \mathrm{GTJ} 20120058$.

Hidalgo C, Martínez P, Medel E and Insa R (2014) 'Characterisation of an unbound granular mixture with waste tyre rubber for subballast layers.' Materials and Structures. Article in press. DOI $10.1617 / \mathrm{s} 11527-014-0443-\mathrm{z}$.

ISO (2003) 'Mechanical vibration and shock. Evaluation of human exposure to whole-body vibration. Part 2: Vibration in buildings (1 to $80 \mathrm{~Hz})$.'

Karlström A and Boström A (2007) 'Efficiency of trenches along railways for trains moving at subor supersonic speeds.' Soil Dynamics and Earthquake Engineering 27:625-641.

Martínez P, Villalba I, Botello F and Insa R (2013) 'Monitoring and analysis of vibration transmission for various track typologies. A case study.' Transportation Research Part D, 24:98-109.

Nakhaei A, Marandi SM, Sani Kermani S and Bagheripour MH (2012) 'Dynamic properties of granular soils mixed with granulated rubber.' Soil Dynamics and Earthquake Engineering, 43:124-132.

Singh B and Vinot V (2011) 'Influence of Waste Tire Chips on Strength Characteristics of Soils.' Journal of Civil Engineering and Architecture, 5 (9):819-827.

Spanish Ministry of Public Works. 'Pliego de Prescripciones Técnicas Generales de Materiales Ferroviarios PF-7: Subbalasto (General Technical Specifications for Railway Materials PF-7: Subballast).' Boletín Oficial del Estado, 2006; 103:16891-16909.

Thompson DJ (2009) Railway Noise and Vibration: Mechanisms, Modelling and Means of control. Elsevier, Oxford.

Wolfe S, Humphrey D and Wetzel E (2004) 'Development of tire shred underlayment to reduce ground-borne vibration from LRT track.' Geotechnical Engineering for Transportation Projects. Proceedings of GeoTrans.126 (I):750-759.

Wolfram Research Inc (2008) Mathematica [Software], version 7.0, Champaign, USA.

Yoon S, Prezzi M, Zia Siddiki N and Kim B (2005) 'Construction of a test embankment using a sandtire shred mixture as fill material.’ Waste Management, 26:1033-1044. 